\title{
Histophilus somni
}

National Cancer Institute

\section{Source}

National Cancer Institute. Histophilus somni. NCI Thesaurus. Code C86441.

A species of facultatively anaerobic, Gram negative, coccobacilli shaped bacteria assigned to the phylum Proteobacteria. This species is nonmotile, catalase negative, oxidase positive, encapsulated and nonacid fast. $\mathrm{H}$. somni is a commensal organism of the ovine and bovine respiratory, vaginal and prepucal mucosa but may become pathogenic, causing infectious meningo encephalitis. 